\title{
Study on Potential Influence of Runoff on Observatory-Based Watershed in Japan
}

\author{
Donglai Ma ${ }^{1,2}$, Seiko Yoshikawa ${ }^{2}$, Yoshiaki Ohsawa ${ }^{1}$, Tadamasa Saito ${ }^{2}$, Masahiro Kobayashi ${ }^{3} \&$ Sadao Eguchi $^{2}$ \\ ${ }^{1}$ Graduate School of Systems and Information Engineering, University of Tsukuba, Tsukuba, Japan \\ ${ }^{2}$ Institute for Agro-Environmental Sciences, NARO (National Agriculture and Food Research Organization), \\ Tsukuba, Japan \\ ${ }^{3}$ Forestry and Forest Products Research Institute, Forest Research and Management Organization, Tsukuba, \\ Japan \\ Correspondence: Donglai Ma, Graduate School of Systems and Information Engineering, University of Tsukuba, \\ 1-1-1 Tennodai, Tsukuba, Ibaraki 305-8577, Japan. Tel: 81-070-1443-9988. E-mail: md18866@gmail.com
}

Received: May 4, $2019 \quad$ Accepted: June 26, $2019 \quad$ Online Published: July 1, 2019

doi:10.5539/jsd.v12n4p19 URL: https://doi.org/10.5539/jsd.v12n4p19

\begin{abstract}
Land use shows the interaction between human and nature, and its impacts especially on runoff have received global attention and required more research studies. However, watershed database is generally available only for very large scales and not yet adapted to small scales. This paper presents a methodology for watershed delineation and potential influence assessment of runoff on the small watersheds in Japan based on the locations of the official observatory point data. Flow direction, flow accumulation, snap pour point and watershed recognition were analyzed by using the D8 algorithm and $10 \mathrm{~m} \times 10 \mathrm{~m}$ DEM data of Japan. Totally 3831 watersheds were delineated by defining snapping pour point distance of $50 \mathrm{~m}$ as the input value, and the nation-wide watershed database was established. According to the suggestion of Notification No. 521 from the Ministry of Land, Infrastructure and Transport of Japan and land use/land cover data from JAXA satellite Alos-2, comprehensive runoff coefficient (CRC) was calculated by the weighted average method and divided into 10 levels by the equal interval method using ArcGIS. The obtained watershed boundary lines were almost identical to the ridge lines in the mountain area which accounts for more than half of Japan. The CRC values in the biggest cities such as Tokyo and Osaka were the highest, indicating these cities would receive the highest impacts of runoff. These results can provide the technical support for the decision-making on watershed management. The creation of small-scale watershed database would provide basic materials for the subsequent research such as flood prevention, water shortage and biogeochemical cycle of the sustainable regional development.
\end{abstract}

Keywords: DEM, watershed delineation, comprehensive runoff coefficient, ArcGIS, Japan

\section{Introduction}

Water is regarded as the most important environmental resource for human survival and development (Khagram Clark, \& Raad, 2003). Water-related measuring stations (including rivers, lakes and reservoirs) are usually set by the river (Pentland, Bathurst, \& Sydor, 1980) which is constantly affected by potential hydrodynamic force. In recent years, a large number of flooding occurred that are not only involved about structural engineering of flood infrastructure or meteorological change (Aktan et al., 1996) but also related to many factors like long term runoff management in upstream area (Kean et al. 2013). Disasters bring a great loss of social capital and follow-up region restoration (White \& Greer, 2011). So, it is necessary to evaluate potential influence of runoff over medium-sized and small-sized watershed scale.

Usually, water-related observatory is not set up on the outlet of the entire basin but somewhere near to the river to easily observe water quality, water level and flow rate, sometimes this is difficult for those concerned personnel to find the upstream contributing area to study the geographical element relationship across the watershed. Watershed delineation is a science (Jensen \& Domingue, 1988; O'callaghan \& Mark 1984; Verdina \& Verdin, 1999) which can reveal all the geographical elements of their relationship inside watershed.

Large-scale watershed delineation usually uses low resolution data to adapt to computer requirements (Priya \& 
Shibasaki, 2001). While sometimes it is not accurate enough for a medium-sized or a small-sized watershed research (Turcotte, Fortin, Rousseau, Massicotte, \& Villeneuve, 2001). Digital elevation model (DEM) is three-dimensional representation of region (Maune, 2007), which is a vector finite sequence $\left\{V_{i}=\left[X_{i}, Y_{i}, Z_{i}\right] ; i=1,2, \ldots, n\right\}$, where $\left(X_{i}, Y_{i}\right)$ is a plane coordinate, $Z_{i}$ is elevation of $\left(X_{i}, Y_{i}\right)$. When the plane points of the vectors in the sequence are arranged in a regular grid, the plane coordinates $\left(X_{i}, Y_{i}\right)$ can be omitted, and then DEM can be simplified, which is a one-dimensional vector sequence $\left\{Z_{i}, i=1,2, \ldots, n\right\}$.

With the rapid development during the high economic growth period of Japan, land use/cover types had a great change (Saizen, Mizuno, \& Kobayashi, 2006). Common consequences of urban development are increased natural environment problems (Priess, 2011). Typically, the annual maximum discharge in a river or a watershed will increase as urban development occurs (Tu, Hall, de Laat, \& de Wit, 2005; White \& Greer, 2006). Runoff coefficient is an important index describing the relationship between land use/cover types and runoff (Giudice, Padulano, \& Rasulo, 2012). However, using runoff coefficient to describe the runoff security on small scale watershed is seldom discussed. Reinforcing all the flood infrastructures across the nation at the same time is impossible especially municipal funds shortage is serious in Japan (Uda, 2015). It is an urgent task to quickly establish countermeasures to assess the potential influence of runoff according to periodic land use change especially in the urban region.

The objective of this study was to establish a watershed database in Japan, in association with the river water observation point based on its location. We used the observatory point data to delineate watershed and evaluate potential influence of runoff on watershed to support sustainable regional development.

\section{Materials and Methods}

\subsection{Data Collection and Pre-Processing}

In this paper we downloaded the $10 \mathrm{~m} \times 10 \mathrm{~m}$ Digital Elevation Model (DEM) from the Geospatial Information Authority of Japan (GSI), totally 4853 pieces including 47 prefectures, XML type files. Land use data were obtained from the Japan Aerospace Exploration Agency (JAXA) satellite Alos-2 (V16.02 10m_res). The observatory point data; which were plotted by the National Institute for Environmental Studies (NIES) of Japan based on the data of National Institute for Environmental Studies (2019) were used to get location information and find the contributing area watershed upstream.

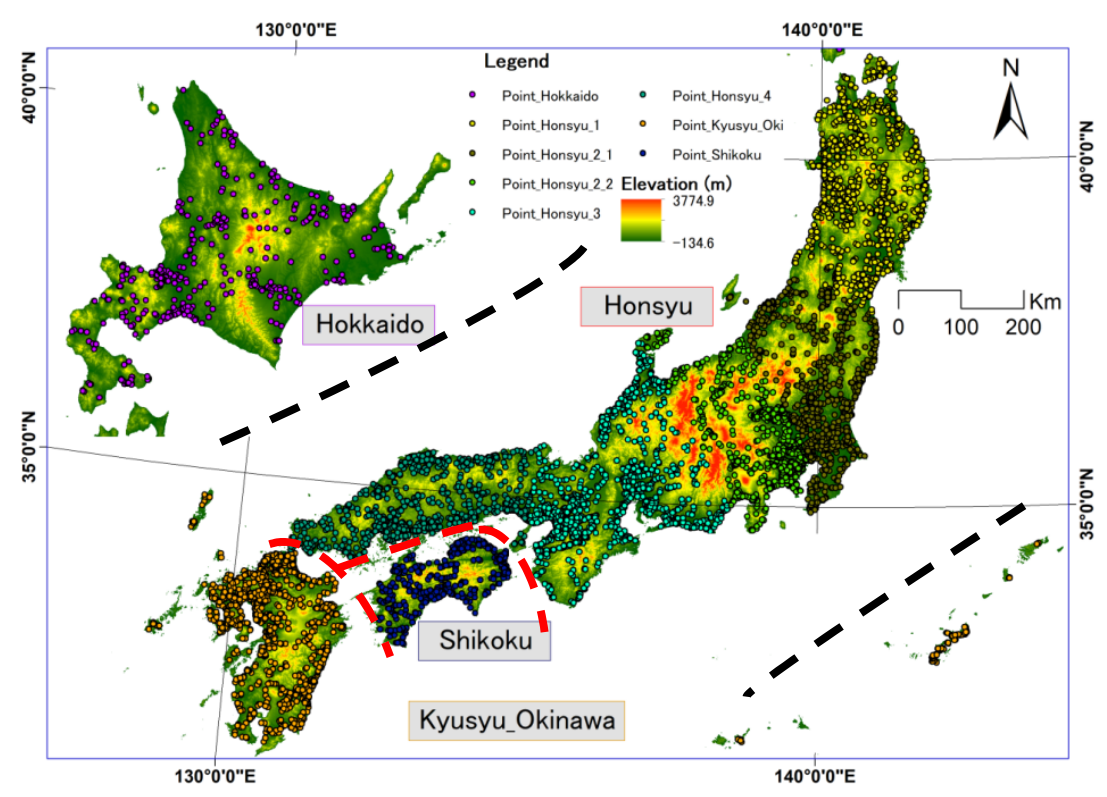

Figure 1. Block calculation of watershed delineation

Firstly, we transferred these data into available format on the GIS software (ArcGIS 10.6.1, ESRI Ltd.,);

Secondly, we redefined geographic coordinate system of the 4853 pieces DEM data as GCS_JGD_2000, and projected coordinate system as JGD_2000_UTM_Zone_54N. Since function 'batch projection' was removed from ArcGIS v10.x, we repaired the toolbox to achieve batch processing as follows: find the Samples.tbx from folder of ArcGIS\Desktop10.6.1\ArcToolbox\Toolboxes, change the file name of 'Samples.tbx' to 'Samples .tbx '(a space is added), reload the ArcGIS Desktop, add the toolbox; 
Thirdly, we removed duplicate values and mosaicked these 4853 pieces DEM data as one, which generated a huge-size file about $450 \mathrm{~GB}$. To improve computing efficiency, we divided the $450 \mathrm{~GB}$ file into 7 blocks (Hokkaido, Honsyu_1, Honsyu_2, Honsyu_3, Honsyu_4, Kyusyu and Shikoku) that correspond to 7 different regions in Japan, as shown in Figure 1. Computer with processor XEON E3-1220 v5 @3.00GHz was used for these above-described steps of pre-processing.

\subsection{DEM Data Analysis Based on D8 Algorithm}

The D8 algorithm is a hydrological process that does not consider the amount of rainfall, soil permeability, vegetation absorption or water blockage, and widely used on research of rivers extraction and watershed delineation. It assumes that rainwater falls on a grid in the terrain, and the water flows to the lowest grid of surrounded eight grids. The advantage is fast calculation which can well reflect the effect of topography on the formation of surface runoff. On the other hand, a shortcoming is also obvious, because it is a single-line transmission, that is the surface runoff water will concentrate on a depression and lead to the phenomenon of cut-off. Thus, it is necessary to fill the depression in the terrain to ensure that the water can also flow out of the depression. Mainly 6 procedures were done as follows:

1) Flow direction analysis

Flow direction is computed for every cell so that the water would flow through it. The value of the cell is a number representing a cardinal direction.

2) Sink

This step uses flow direction grid to identify sinks in DEM. These are areas surrounded by higher areas, so that there is no external drainage. Sometimes sinks are real, but often DEMs have erroneous sinks. Regardless of whether they are real or not, for the watershed delineation process to work, here we need a 'depression less DEM' with no sinks. Before the next step, we need to check that there are no conflicts in the fixage, minage or maxage nodes of the input tree to avoid terminating the program and displaying an error message. The official help of ArcGIS did not specify what kind of processing would be done after finding the sink after using the 'sink' tool. The depressions usually appear on almost flat plains which distributes with a large area. Most users ignored the importance of sink and fill if there is a real depression; however, this would lead to serious analysis error.

3) Fill

This step will fill the sinks of DEM. We did both a basic Fill command and some $Z$ value tests. The result of this step will generate a less depression DEM which will in turn be the basis of the rest of the process.

4) Flow accumulation

This step calculates for each cell in the filled DEM array, the number of cells from which the water flows in. Areas of higher flow accumulation values are where water collects and drains. Thus, the areas of very high values are likely perennial streams or rivers, and areas with lower values may be intermittent streams. The flow accumulation grid will allow the software to determine the area draining to any specified point on the DEM.

\section{5) Snapping pour point}

Though most of observation points for river water quality locate on or beside rivers, each observation point has different distance from the river, this need to be tested a lot of times. When observation point located near multiple rivers, it may capture the flow accumulation grid corresponding to other rivers. Especially when the distance between multiple pour points is relatively close, a reasonable search distance needs to be set. Errors will be inevitably produced in the flow path determination by. In this study, we tested the distance with every $5 \mathrm{~m}$ interval from 0 to $300 \mathrm{~m}, 60$ times, using the visual programming of ArcGIS.

6) Watershed

This command performs the watershed delineation based on snapped pour point by observation point data and calculates the contributing area in upstream.

Because these steps 1) to 6) are common hydrological analysis based on ArcGIS, this paper omits some of the accompanying figures.

\subsection{Land Use Data Processing}

We did batch definition of projection the same as the processing of DEM data and according to the former research (Brath et al. 2006; Naef et al. 2002), we reclassified the land use/land cover data into 6 types; i.e., waters is 1 , urban area is 0.9 , paddy field is 0.7 , crop and grass field is 0.3 , forest is 0.2 and bare land is 0.4 , as shown in Table 1. 
Table 1. Runoff coefficient criteria

\begin{tabular}{ccc}
\hline Serial number & Land use/cover & Runoff coefficient \\
\hline 1 & Waters & 1 \\
2 & Urban area & 0.9 \\
3 & Paddy field & 0.7 \\
4 & Crop and grass field & 0.3 \\
5 & Forest & 0.2 \\
6 & Bare land & 0.4 \\
\hline
\end{tabular}

\subsection{Comprehensive Runoff Coefficient (CRC)}

Weighted average method was used to calculate the comprehensive runoff coefficient (CRC) with the suggestion of Notification No. 521 from the Ministry of Land, Infrastructure and Transport. The expression is as follows:

$$
Q_{j}=\sum_{i=1}^{n} q_{i j} * a_{i j} / S_{j}
$$

where $Q_{j}$ is CRC of watershed $j ; q_{i j}, a_{i j}$ is respectively runoff coefficient and area of land use type $i$ of watershed $j ; S_{j}$ is the total area of watershed $j ; n$ is the number of land use type.

\section{Results and Discussion}

Through the above analysis using D8 method, with high-resolution DEM data, Land Use data and runoff coefficient criteria of Japan by ArcGIS, several findings were obtained as summarized below.

\subsection{Watershed Delineation and Distribution}

In this study, we repeated the procedure of 'Snapping pour point' by ArcGIS visual programming which defined $50 \mathrm{~m}$ as the snapping pour point distance input value to complete the calculation for every observation point.

Out of 7381 observation points, totally 3813 watersheds were delineated availably. The average extraction success rate of whole Japan was $51.6 \%$. The code \#2 (Honsyu_1) showed the highest extraction success rate of $60.6 \%$, while code \#4 (Honsyu_3) showed the lowest of $40 . \overline{7} \%$ (Table 2). According to the former research (Turcotte et al. 2001). a watershed delineated by D8 method would be an irregular geometry polygon with countless vertices. Thus, we set a threshold that the polygon of sub-watershed area with more than 50 vertices considered to be correct and saved without those too small and too simple geometry watersheds according to our visual judgment. The framework of programming is shown in Figure 2.

There are also many observation points belonging to the same river and this is because it contains many important tributaries to be observed, where many people are living there. However, in such cases, watershed delineation leads to produce overlapping watersheds. Such a result is usually difficult to display on a map. Figure $3 \mathrm{~b}$ shows the overlapping watersheds not very friendly, but watershed boundary was well delineated in the central part of Japan, which corresponds mainly to the mountain area (Figure 3a), while fewer watersheds along the coastline areas.

Table 2. Relationship between snapping pour point and number of valid watersheds

\begin{tabular}{ccccc}
\hline Code $(\#)$ & Name of Block & Observation Points & Valid watershed & Success rate \\
\hline$\# 1$ & Hokkaido & 424 & 230 & $54.2 \%$ \\
$\# 2$ & Honsyu_1 & 966 & 585 & $60.6 \%$ \\
$\# 3$ & Honsyu_2 & 1598 & 848 & $53.1 \%$ \\
$\# 4$ & Honsyu_3 & 1399 & 569 & $40.7 \%$ \\
$\# 5$ & Honsyu_4 & 974 & 514 & $52.8 \%$ \\
$\# 6$ & Kyusyu & 1544 & 831 & $53.8 \%$ \\
$\# 7$ & Shikoku & 483 & 236 & $48.9 \%$ \\
& Total & 7388 & 3813 & $51.6 \%$ \\
\hline
\end{tabular}




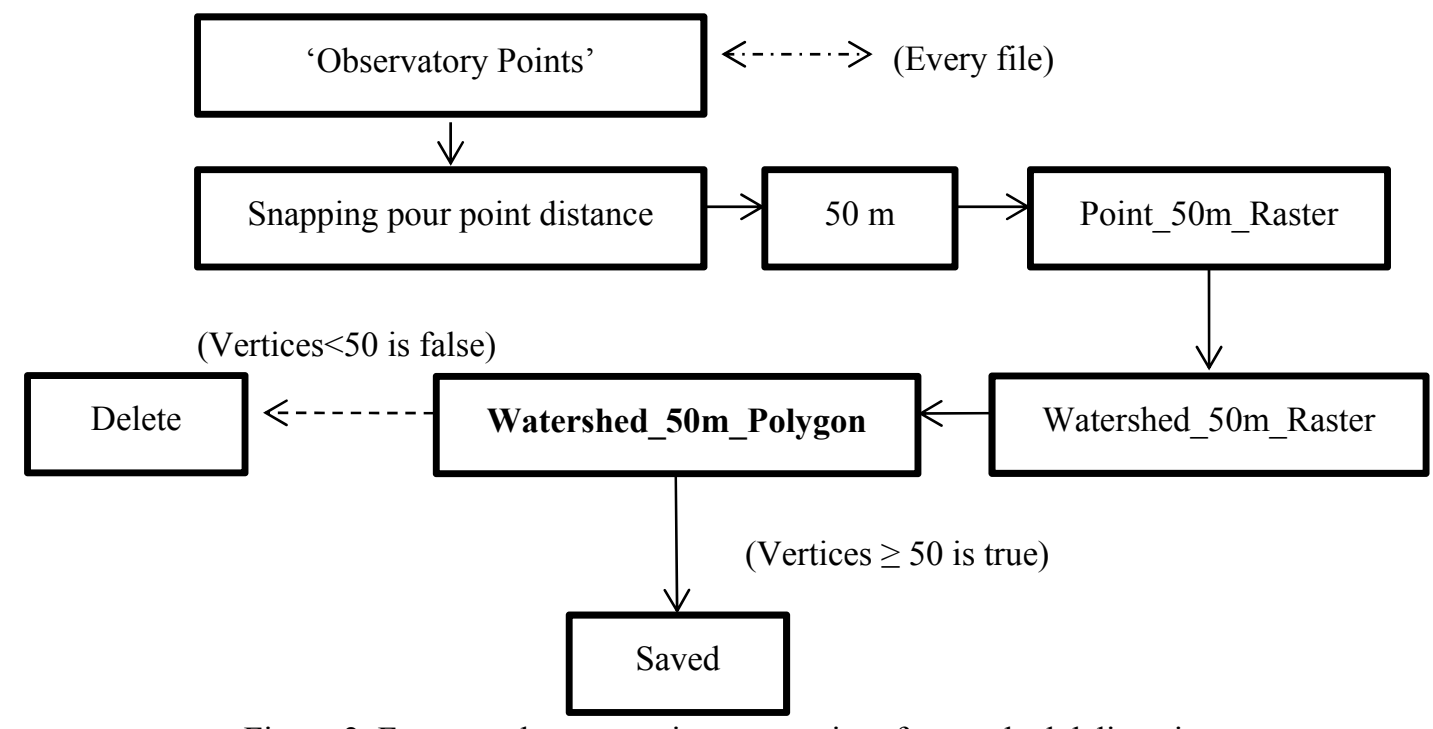

Figure 2. Framework on snapping pour point of watershed delineation

Along the coastline area, watershed cannot be accurately drawn out because there are too many flat lands and artificial rivers that are not recognized by the $10 \mathrm{~m}$-resolution DEM data.

Observation point data-based watershed database is preliminarily established. This is very important for the subsequent research such as flood prevention, nutrient movement and watershed management for the sustainable regional development.

\subsection{Potential Influence of Runoff on Small Watershed Scale}

Calculation of the CRC was done by combination of land use data (Figure 4a) using the 'tabulate area' of ArcGIS10.6.1. According to the watershed delineation results, in another word, influence of runoff on 3813 watersheds was preliminary evaluated and classified into 10 grades by the equal interval method. The spatial distribution (Figure $4 \mathrm{~b}$ ) showed that the CRC values were significantly high (0.7-1.0) in metropolitan area of Tokyo, Osaka and a small part of Niigata; this is because serious urbanization happened in these areas with substantial land use changes. The CRC values in Southwest part of Hokkaido, central of northeast part in mainland, north of Kyusyu island and the watershed where the major cities located were middle (0.4-0.6) due to the moderate urbanization in these areas. The rest area with mild urbanization showed low CRC values $(0.1-0.3)$ which had less impact on the watershed scale hydrology. The result indicated that the more the urbanization the runoff becomes larger and the downstream areas become to be affected by more runoff. 
3a)

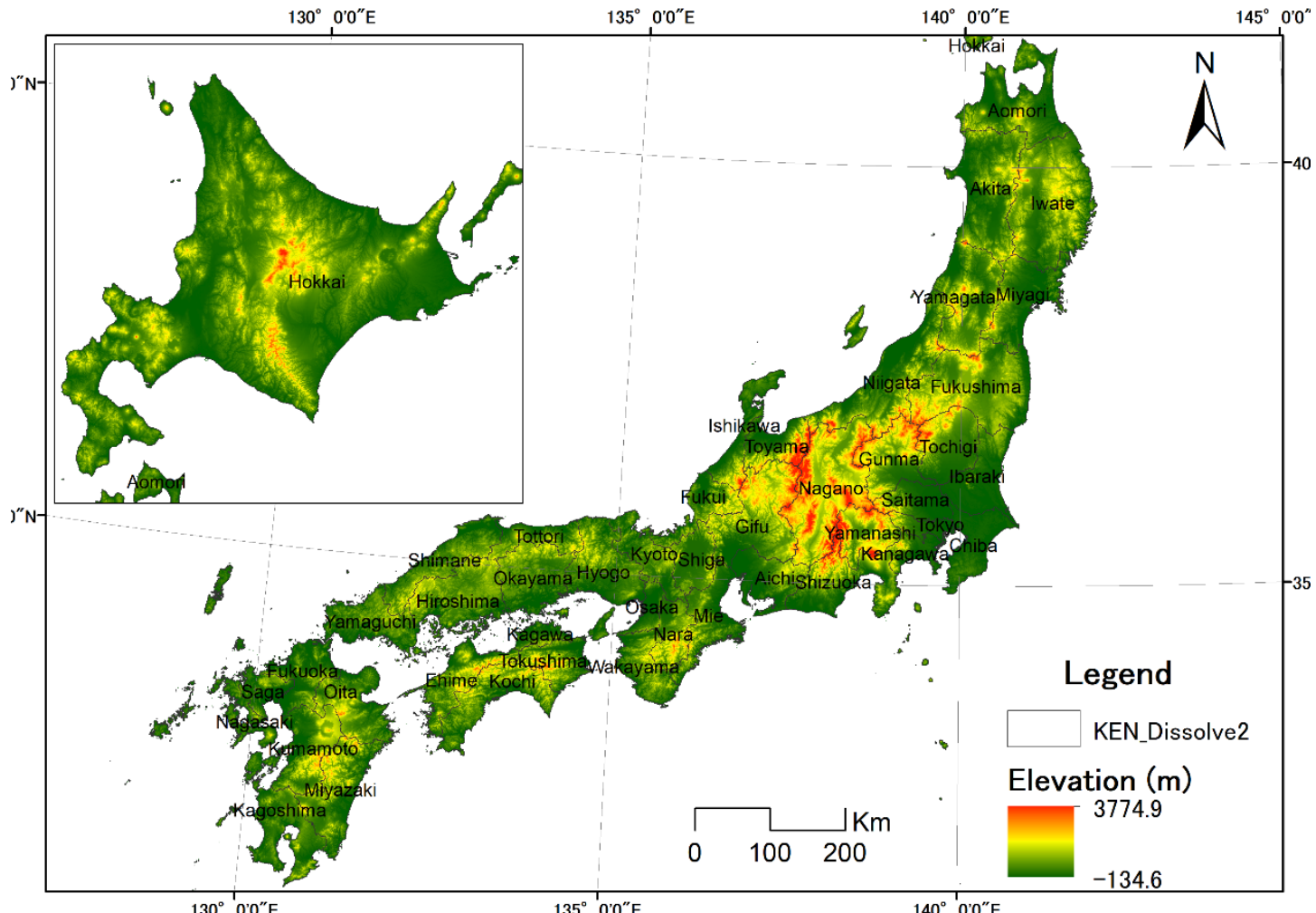

$3 b)$

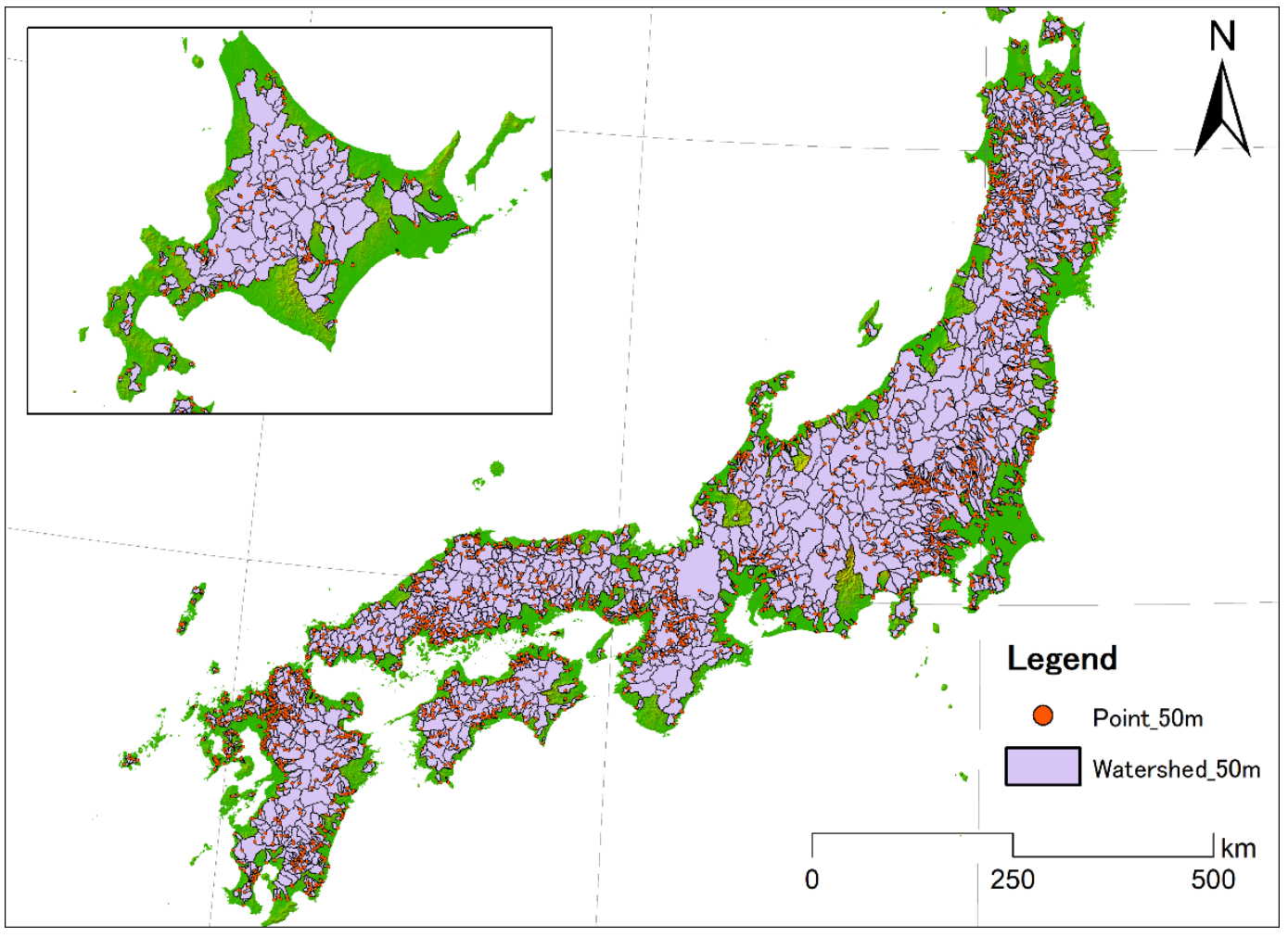

Figure 3. Mosaicked DEM of Japan (3a) and 50 m-based watershed delineation (3b) 
4a)

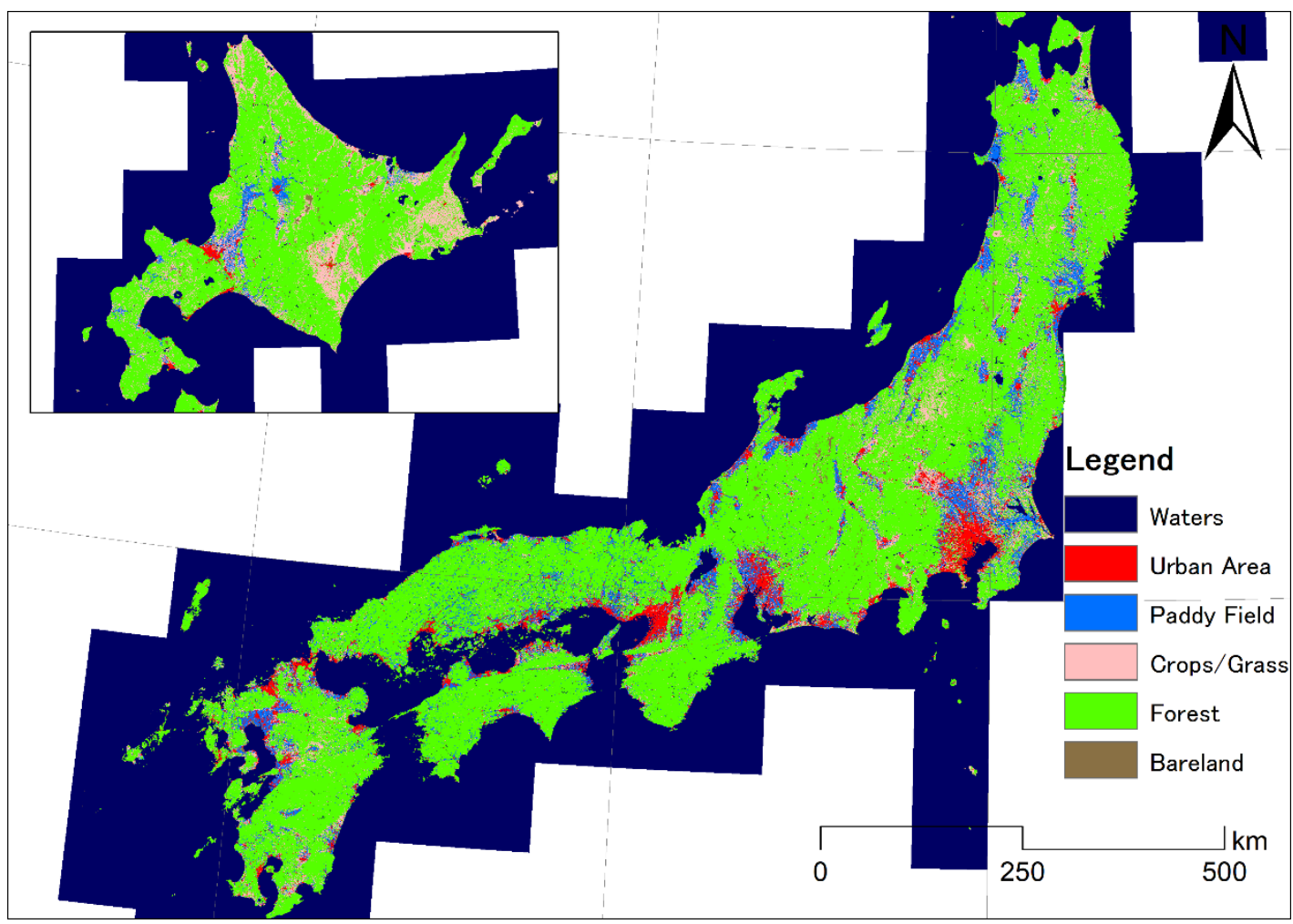

4b)

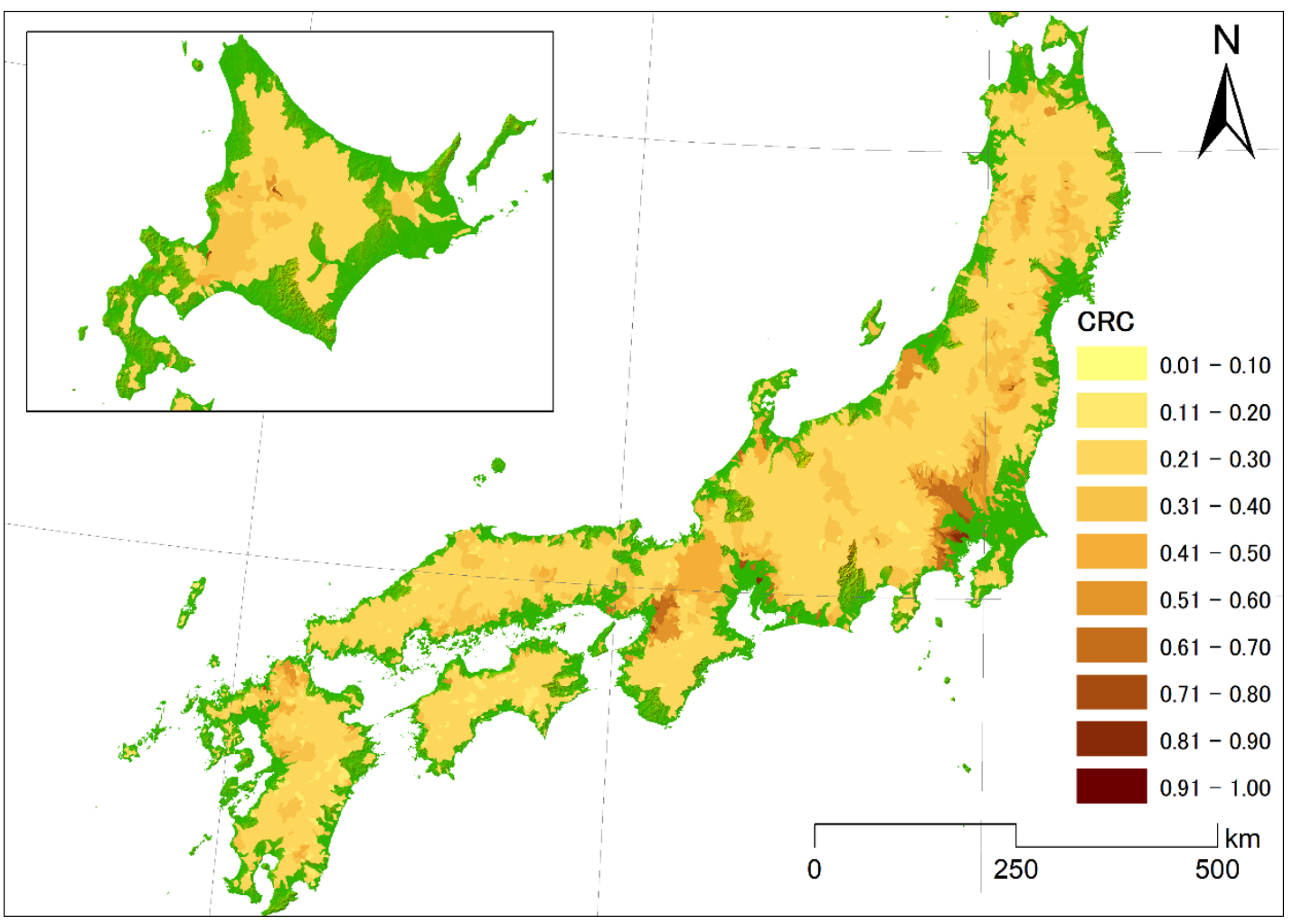

Figure 4. Land use map (4a) and 50 m-based comprehensive runoff coefficient map (4b) 


\subsection{Other Finding}

'Fill' tool of hydrological analysis was started from the ArcGIS Version 8.x in the early 2000s. In this study, we recognized that the 'Fill' command has already updated the automatic calculation of $Z$ value for users, while the official help of ArcGIS does not mention this.

\section{Conclusions}

In this study, we established a watershed database in Japan, in association with the river water observation point based on its location. Because of some inevitable problems, current database is relatively small; however, subsequent updates are indispensable in future using not only D8 but some other extraction methods.

Regarding the comprehensive runoff coefficient (CRC), potential influence of runoff in a watershed will generally be evaluated despite different criterion might get different results. Also watershed delineation based on different point data should of course produce different watersheds. However, we have to mention that our study revealed the objects in the downstream of the watershed will be more affected by runoff.

With the continuous updating and improvement of Remote Sensing data, DEM data and hydrological information extraction technology in future (McCabe, Rodel, Alsdorf, Miralles, \& Uijlenhoet, 2017), the accuracy of watershed delineation will also be improved, especially for the flat areas which should have a certain impact on watershed analysis and calculation (Garbrecht and Martz 1997). Such progresses are of a great significance in further water-related research such as digital watershed construction, non-point source pollution, nutrient movement and flood prevention for the regional sustainable development.

\section{Acknowledge}

This study was financially supported by Grant-in-Aid for Scientific Research (B) from Japan Society for the Promotion of Science. We acknowledge Geospatial Information Authority of Japan (GSI), Space Technology Directorate for providing DEM data and LULC data. The original meaturing point data were collected by National Institute for Environmental Studies (NIES) of Japan.

\section{References}

Aktan, A. E., Farhey, D. N., Brown, D. L., Dalal, V., Helmicki, A. J., Hunt, V. J., \& Shelley, S. J. (1996). Condition assessment for bridge management. Journal of Infrastructure Systems, 2, 108-117. https://doi.org/10.1061/(ASCE)1076-0342(1996)2:3(108)

Brath, A., Montanari, A., \& Moretti, G. (2006). Assessing the effect on flood frequency of land use change via hydrological simulation (with uncertainty). Journal of Hydrology, 324, 141-153. https://doi.org/10.1016/j.jhydrol.2005.10.001

Emily, C. W., \& Virgil, H. S. (2011). Social Capital as Collective Narratives and Post-Disaster Community Recovery. Sociological Review, 59, 266-282. https://doi.org/10.1111/j.1467-954X.2011.02008.x

Garbrecht, J., \& Martz, L. W. (1997). The assignment of drainage direction over flat surfaces in raster digital elevation models. Journal of Hydrology, 193, 204-213. https://doi.org/10.1016/S0022-1694(96)03138-1

Giudice, G. D., Padulano, R., \& Rasulo, G. (2012). Factors affecting the runoff coefficient. Hydrology and Earth System Sciences, 9, 4919-4941. https://doi.org/10.5194/hessd-9-4919-2012

Jensen, S. K., \& Domingue, J. O. (1988). Extracting topographic structure from digital elevation data for geographic information system analysis. Photogrammetric Engineering and Remote Sensing, 54, 1593-1600.

Kean, J. W., McCoy, S. W., Tucker, G. E., Staley, D. M., \& Coe, J. A. (2013). Runoff-generated debris flows: Observations and modeling of surgeinitiation, magnitude and frequency. Journal of Geophysical Research, 118, 2190-2207. https://doi.org/10.1002/jgrf.20148

Khagram, S., Clark, W., \& Raad, D. F. (2003). From the Environment and Human Security to Sustainable Security and Development. Journal of Human Development and Capabilities, 4, 289-313. https://doi.org/10.1080/1464988032000087604

Maune, D. F. (2007). Digital Elevation Model Technologies and Applications: The DEM Users Manual. USA, American Society for Photogrammetry and Remote Sensing.

McCabe, M. F., Rodel, M., Alsdorf, D. E, Miralles, D. G., Uijlenhoet, R., Wagner, W. ... Wood, E. F. (2017). The future of Earth observation in hydrology. Hydrology and Earth System Sciences, 21, 3879-3914. https://doi.org/10.5194/hess-21-3879-2017 
Mori, N., Takahashi, T., Yasuda, T., \& Yanagisawa, H. (2011). Survey of 2011 Tohoku earthquake tsunami inundation and run - up. Geophysical Research Letters. https://doi.org/10.1029/2011GL049210

Naef, F., Scherrer, S., \& Weiler, M. (2002). A process-based assessment of the potential to reduce flood runoff by land use change. Journal of Hydrology, 267, 74-79. https://doi.org/10.1016/S0022-1694(02)00141-5

O'callaghan, J. F., \& Mark, D. M. (1984). The extraction of drainage network from digital elevation data. Computer Vision Graphics and Image Processing, 28, 323-344. https://doi.org/10.1016/S0734-189X(84)80011-0

Pentland, R. L., Bathurst, J., \& Sydor, M. (1980). Water Planning and Management in Canada. Water International, 5, 22-34. https://doi.org/10.1080/02508068008685873

Priess, J. A., Schweitzer, C., Wimmer, F., Batkhishig, O., \& Mimler, M. (2011). The consequences of land-use change and water demands in Central Mongolia. Land Use Policy, 28, 4-10. https://doi.org/10.1016/j.landusepol.2010.03.002

Priya, S., \& Shibasaki, R. (2001). National spatial crop yield simulation using GIS-based crop production model. Ecological Modelling, 136(2-3), 113-129. https://doi.org/10.1016/S0304-3800(00)00364-1

Saizen, I., Mizuno, K., \& Kobayashi, S. (2006). Effects of land-use master plans in the metropolitan fringe of Japan. Landscape and Urban Planning, 78, 411-421. https://doi.org/10.1016/j.landurbplan.2005.12.002

Tu, M., Hall, M. J., de Laat, P. J. M., \& de Wit, M. J. M. (2005). Extreme floods in the Meuse river over the past century: aggravated by land-use changes? Physics and Chemistry of the Earth, 30, 267-276. https://doi.org/10.1016/j.pce.2004.10.001

Turcotte, R., Fortin, J.-P., Rousseau, A. N., Massicotte, S., \& Villeneuve, J.-P. (2001). Determination of the drainage structure of a watershed using a digital elevation model and a digital river and lake network. Journal of Hydrology, 240, 25-242. https://doi.org/10.1016/S0022-1694(00)00342-5

Uda N. (2015). Japan: Fiscal Discipline of Local Governments. Japan, Ministry of Finance.

Verdina, K. L., \& Verdin, J. P. (1999). A topological system for delineation and codification of the Earth's river basins. Journal of Hydrology, 218, 1-12. https://doi.org/10.1016/S0022-1694(99)00011-6

White, M. D., \& Greer, K. A. (2006). The effects of watershed urbanization on the stream hydrology and riparian vegetation of Los Peñasquitos Creek, California. Landscape and Urban Planning, 74, 125-138. https://doi.org/10.1016/j.landurbplan.2004.11.015

\section{Copyrights}

Copyright for this article is retained by the author(s), with first publication rights granted to the journal.

This is an open-access article distributed under the terms and conditions of the Creative Commons Attribution license (http://creativecommons.org/licenses/by/4.0/). 